\title{
Effect of Electric Field Distribution on Pulse Electrochemical Machining of Small Holes with Tubular Electrode
}

\author{
Zhaolong $\mathrm{Li}^{\mathrm{a}}$, Baocheng Xie ${ }^{\mathrm{a} *}$, Yangwei Wang ${ }^{\mathrm{b}}$ \\ ${ }^{a}$ School of Mechanical and Power Engineering, Harbin University of Science and \\ Technology, Harbin, Heilongjiang Province 150080, China \\ ${ }^{b}$ Nanjing University of Aeronautics and Astronautics, Jiangsu Key Laboratory of \\ Precision and Micro-Manufacturing Technology, Nanjing, Jiangsu Province 210016, \\ China \\ xiebaocheng@hrbust.edu.cn

\section{Abstract} \\ Electrochemical machining (ECM) of holes on the surface of nickel-based alloy as tool \\ electrode was investigated to analyze the effect of electric field distribution on hole forming \\ process in ECM of small holes. Based on the experimental and simulation results, it was \\ shown that the law of electric field distribution in electrochemical machining gap with \\ tubular electrode and the effect of gap electric fletd on dimension of hole were illustrated. In \\ addition, the influences of electrolyte pressure on electric field distribution and stability of \\ machining was studied to conclude the effective factors of machining stability in ECM of \\ holes.
}

Keywords: Electrochemical machining (ECM), tubular electrode, electric field distribution, electrolyte pressure

\section{Introduction}

It is difficult to machine ultradeep louver of which diameter is $1-4 \mathrm{~mm}$, depth-diameter ratio is in the range 40 to 150 and even 500 in the aero-engine turbine blade by using the general machining or otherprocessing methods. Owing to high requirements to shape accuracy and surface quality of louvers, people adopt tubular electrode to machine electrochemically at present. [1-5]A major problem existed in electrochemical machining with tubular electrode is poor machining stability. Typically we reduce machining gap in order to ensure stape and dimensional accuracy of holes [6-9]. And controlling electric field distribution inside the machining gap is the essence of guaranteeing machining gap.

This paper investigates the influence of electric field distribution on hole machining in the process of ECM with tubular electrode, and analyzes the law of different electrode feed rate impacting on forming hole. As a result of our experiments were concluded the law of electric fiele distribution in electrochemical machining gap with tubular electrode and analyzed not only law of gap electric field impacting on diameter of hole and depth of hole but also reasons of affecting stability of machining holes electrochemically with tubular electrode.

\section{The Experiment Design}

The following are experimental conditions:(1) Initial gap between tubular electrode and workpiece is $1 \mathrm{~mm}$. (2) Tool feed speed is set to zero (3) It is about 4 minutes when the gap current is zero while electrochemical machining ends and a hole is machined on the surface of 
the workpiece. (4) An insulating layer covers the outside of the tubular electrode. Electrolysis reaction occurs only at the front-end surface of the tubular electrode. The electrolyte pressure is $2.4 \mathrm{MPa}$ when electrolytes jet to the workpiece surface from the interior of the tubular electrode. Analyze effect of machining gap on radius and depth of holes as well as impact of pulse width and pulse interval on forming holes. Experiments are conducted on self-developed pulse electrochemical machining machine tool. Figure 1 shows equipment comprise a workbench, the electrolyte flow system, pulse power etc. Figure 2 is schematic diagram for tubular electrode $(2.1 \mathrm{~mm}$ diameter) covered with an insulating layer.

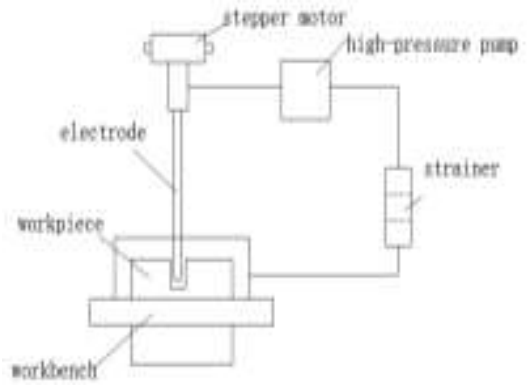

Outer radius of bare tool

Figure 1. Structure Diagram of ECM Equipment

\section{Analysis of Experimental Data}

Figure 3 shows that fixed pulse intervalis $500 \mu \mathrm{s}$ and pulse width is enlarged from $1900 \mu \mathrm{s}$ to $2100 \mu \mathrm{s}$ while diameter of hole is increased from $2.9 \mathrm{~mm}$ to $3.1 \mathrm{~mm}$. Figure 4 is a histogram for depth of electrolytic hole that is licreased from $1 \mathrm{~mm}$ to $1.3 \mathrm{~mm}$ with pulse width enlarged. With the increase of pulse width, electrolytic diameter of hole is increased by $22 \%$ and depth of electrolytic hole is increased by $35 \%$.

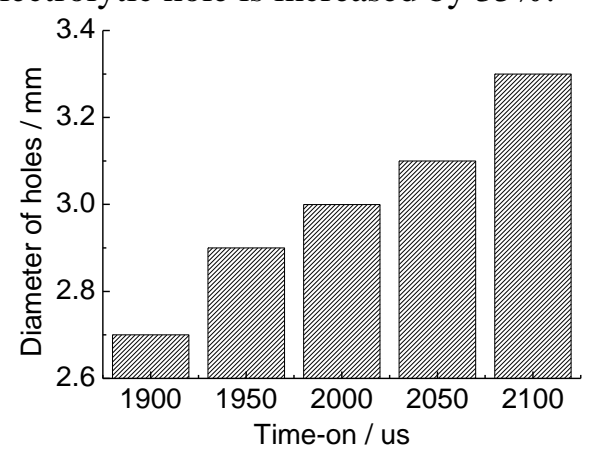

Figure 3. Influence of Pulse Width on the Semi Diameter of the Hole

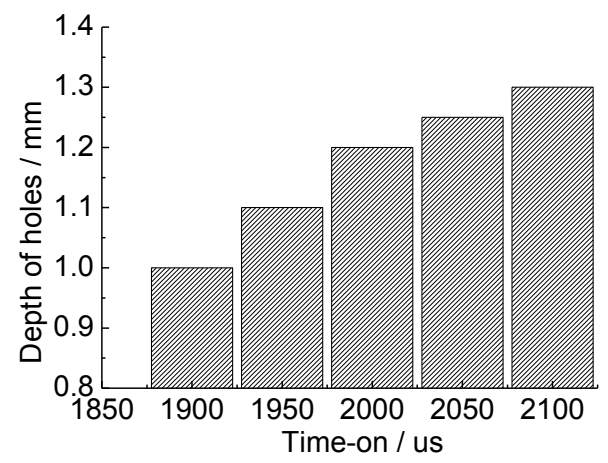

Figure 4. Influence of Pulse Width on the Processing Depth of ECM

As is shown in Figure 5 and Figure 6, when the tubular electrode maintains a certain speed, within a fixed duty cycle diameter of hole is inverse proportion to tool feed rate and gap current is proportional to tool feed rate. This is because average dissolution rate of the workpiece is constant in the condition of fixed duty cycle electrolysis within unit time is shortened with the increase of the feed rate of the tubular electrode. Therefore gap of unilateral side of hole is reduced. With the increase of tool feed speed, decreasing of front-end machining gap results in increase of front-end processing current If and total processing current I. 


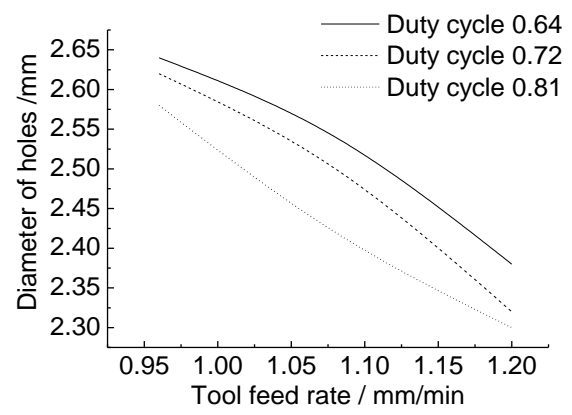

Figure 5. Influence of Tool Electrode Feed Rate on the Unilateral Space of Processed Hole

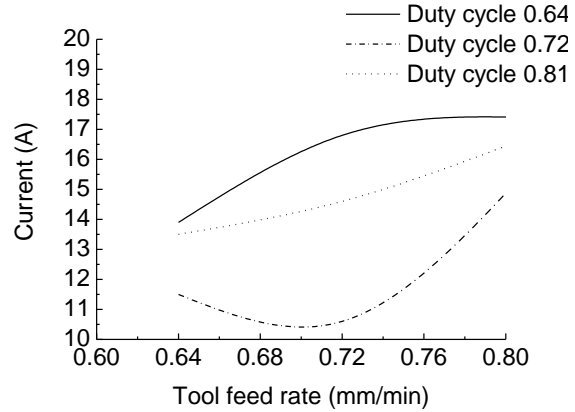

Figure 6. Influence of Tool Electrode Feed Rate on the Electric Current in the Gap

\section{Analysis of Stability of ECM}

Internal machining gap voltage is low, and microstructure of the end surface of the tubular electrode into undulating shape. As shown in Figure 7 since the height of point $\mathrm{A}$ is different from point B's, voltage of point B is lower than point A's at the moment of low voltage. So the electric field is formed between point $A$ and point $B_{4}$ Oxygen adsorption is formed in point A. And non-metallic particles are oxidized near the point A. Such moments of low voltage appear periodically in the tubular eleetrode electrochemical machining process by using pulse power. In the whole end surface of the tubular electrode periodic appearing of numerous electric fields like electric field $\mathrm{AB}$ accelerates the formation of nonmetal film on the surface of tubular electrode and increases the frequency of short circuit. Observe morphology of end surface of tool electrode by seanning electron microscope. Figure 8 shows that there are massive nonmetals in the end surface of the tool electrode by analyzing EDX spectrum.
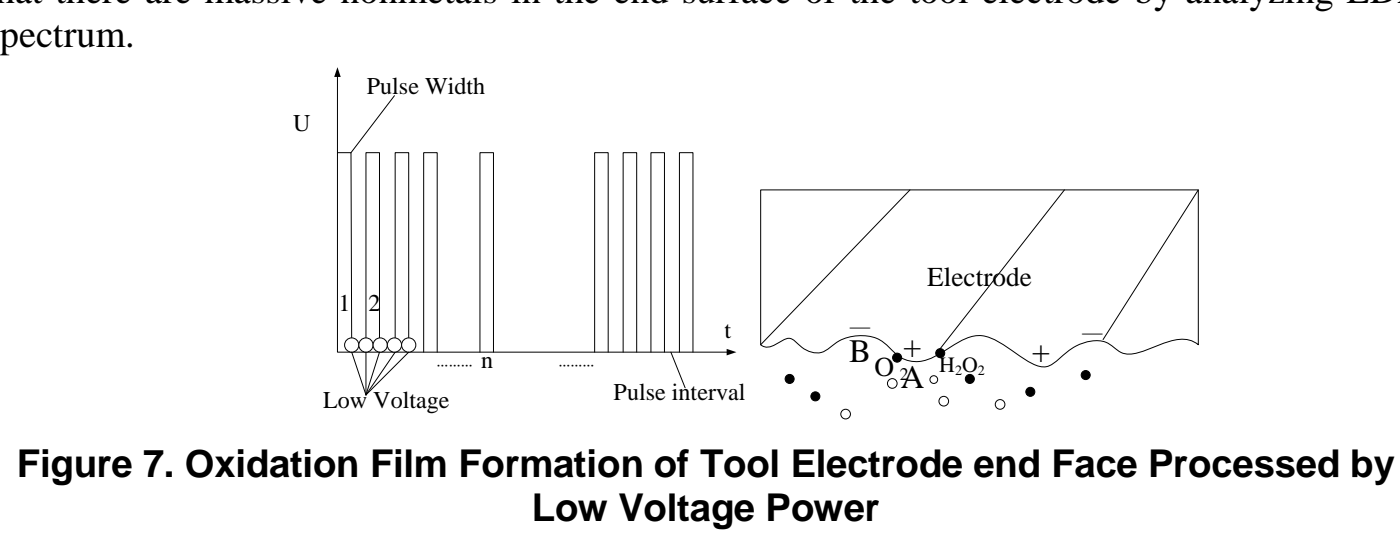


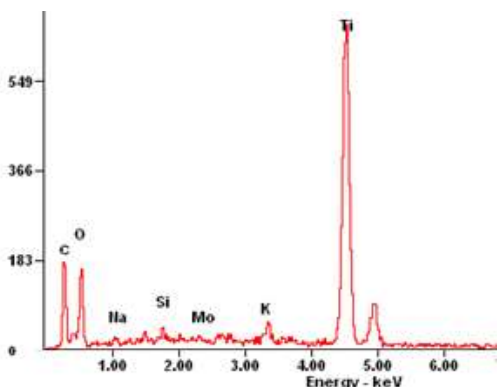

Figure 8. EDX Spectrum of Tool Electrode End Face after Short Circuit

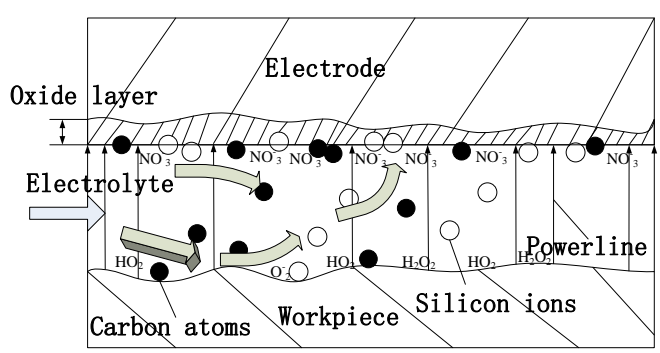

Figure 9. Oxidation Film Formation of Tool Electrode End Face

It can be inferred that non-metallic particles on the surface of the tubular electrode generate a variety of oxide to form film. As presented in Figure 9 the end surface of tubular electrode due to film formed by carbon and silicon carbon, silicon and the nonmetal affect to machine gap field, thereby cause frequent short circuit.

\section{Effect of Electrolyte Pressure on Electric Field Distribution}

There are bubbles on the surface of toon electrode in the electrolysis process. These bubbles not exist in the electrolyte near the tool electrode, but firmly absorbed on the surface of tool electrode. This is because bubbles in the electrolyte around the tubular electrode stress unevenly. Pressure causes bubbles tightly pressed on the end surface of the tubular electrode, as shown in Figure 10. Since electroal conduetivity of bubble is bad, bubbles are firmly pressed against the end surface of the tubular electrode by pressure of electrolyte, which greatly affects the electric field strength in the ECM loop. It weak current of electrochemical machining gap reduces conductivity of electrolyte inside electrochemical machining gap and impacts gap electric field of ECM holes. Meanwhile it is concluded from Figure 11 and Figure 12 that transverse pressure distribution of gap A-B in the front end of the straight hole is $M$ shape and distribution of gap pressure is symmetrical and regressive. Symmetry of distribution of electrolyte pressure guarantees the stability of the tool electrode at the time of increasing pressure on the electrolyte, thereby ensuring the stability of the gap electric field.

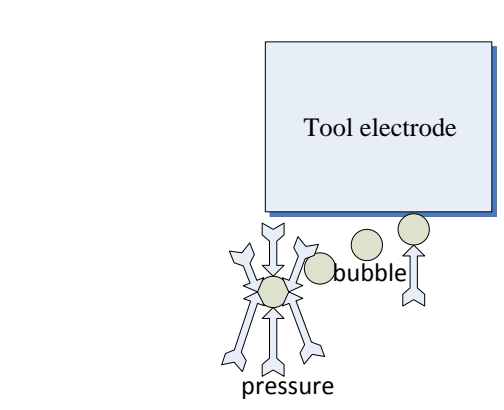

Figure 10. The Bubble Adsorption in the Processing Gap

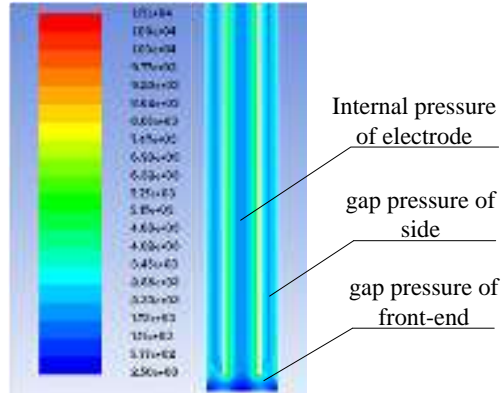

Figure 11. Simulation of Pressure of Machining Gap 

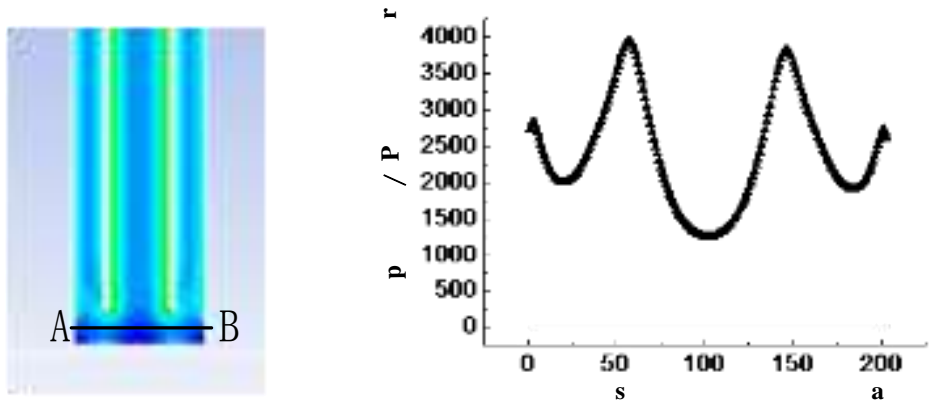

Figure 12. Lateral Pressure Distribution of Gap of Front-end Hole

In the test, pulse width is in the range of $500-1000 \mu \mathrm{s}$, pulse voltage is $24 \mathrm{~V}$, electrolyte pressure in the range of 1.9-3.0MPa. Figure 13 shows that gap of unilateral side of hole decreases with electrolyte pressure increasing at a fixed time. This is because as the electrolyte pressure increases, bubbles within electrochemical machining gap the reaction product and the heat of reaction was promptly taken away it renews the electrolyte and improves the localization of machining hole by increasing the accuracy of the shape of electrochemical machining hole.

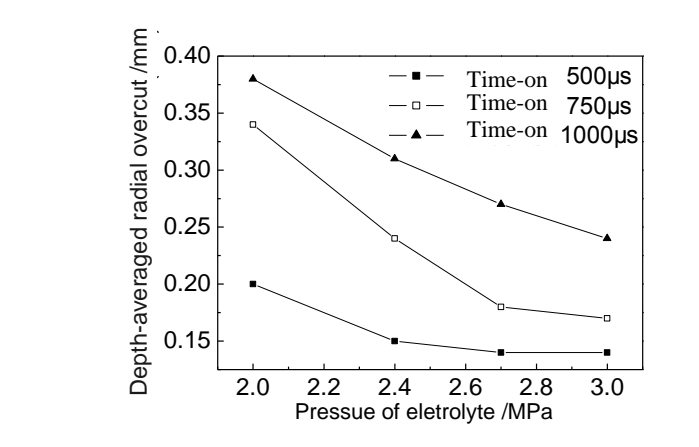

Figure 13 Influence of Electrolyte Pressure on the Unilateral Space of Q Processed Hole

\section{Effect of Curve Hole Structure on Electric Field Distribution}

Machining curve hole by ECM mainly researches structure of key curve holes of aero-engine turbine blade. Processing method is the combination of memory alloy tubular electrode and of ECM. This method can machine curve hole whose structure is the same as tubular electrode by memory alloy tubular electrode that has the characteristic of shape memory after training. In the electrolysis reaction, metal materials are corroded in macroscopic view. The fact is the microscopic collection that redox reactions on the positive and negative electrode cause ions transferring. Figure 14 is a schematic diagram for ions transferring between positive electrode and negative electrode. 


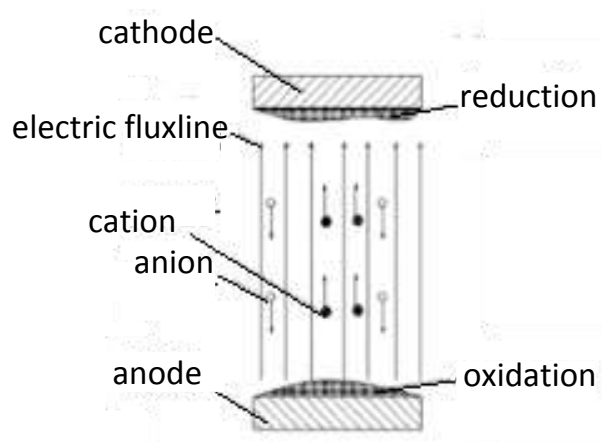

Figure 14. Schematic Diagram of Electrode Reaction

During the entire process, effect of electrode potential on electron transfer speed is the core of whole process of the electrode core, which has a significant impact on the speed of the electrolytic reaction and the direction. Based on principle of chemical dynamics reactive ions must absorb certain energy to reach an unstable transition state active state. Then reactive ions participate in the reaction. Therefore, in electrochemical reaction, activation of oxidation or reduction impacts the process of poles moving between positive and negative electrodes. As shown in Figure 15, current within machining gap can be divided/into front-end current and side current when using tubular electrode covered with the insulating layer to machine holes. Therefore controlling the electric current magnitude and the current distribution is the key technology of the pulse electrochemicâl machining with tubular electrode.

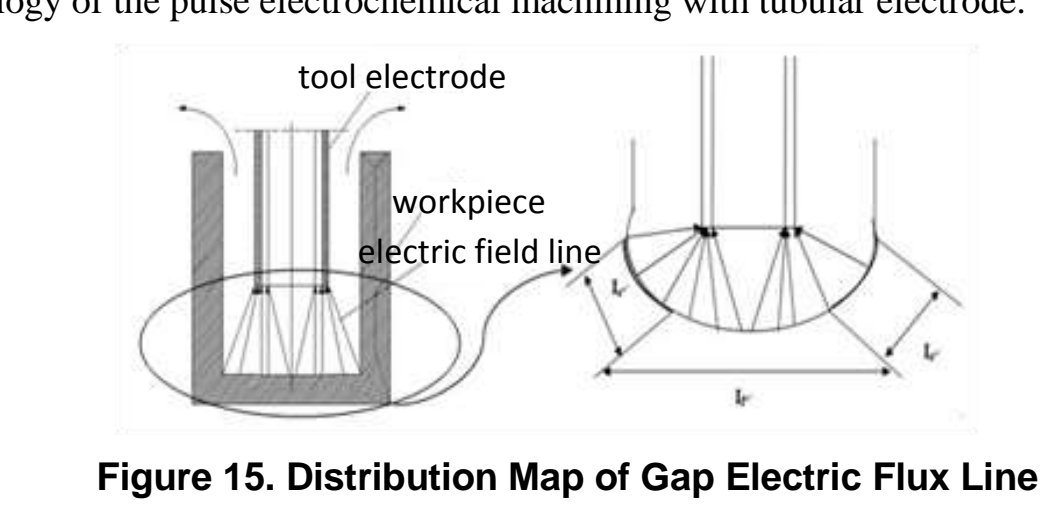

Electric field inside the machining gap changes because curvilinear motion of memory alloy tool electrode occurs in process of machining curve holes. During curvilinear motion of memory alloy, toolelectrode if not change the intensity of the electric field inside the gap, processing errors are caused due to curvilinear motion of memory alloy tool electrode as shown in Figure 16 In order to avoid false processing it needs to match gap electric field of ECM that machines curve holes and curvilinear motion of memory alloy tool electrode to a oid-processing errors of workpiece due to deformation of memory alloy tool electrode. Mean wile ensuring stability of processing is an important measurement to control intensity of the gap electric field.

When using bending motion of memory alloy tool electrode to machine curve hole distance of the end of memory alloy tool electrode deformation and workpiece is reduced due to memory alloy tool electrode deformation. It increases the number of bubbles on the end surface of memory alloy tool electrode deformation as shown in Figure 17 and reduces electric field intensity of curve hole ECM gap in the direction of memory alloy tool electrode deformation. Thereby affect local removal rate of curve hole electrochemical machining. If 
memory alloy tool feed rate is greater than removal rate of curve hole electrochemical machining in the direction of memory alloy tool electrode deformation, it will cause a short circuit.

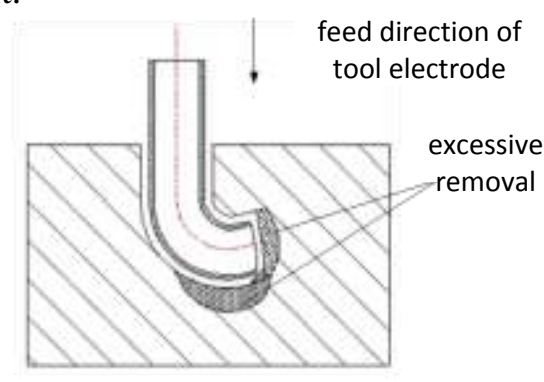

Figure 16. Schematic Diagram of Processing Error

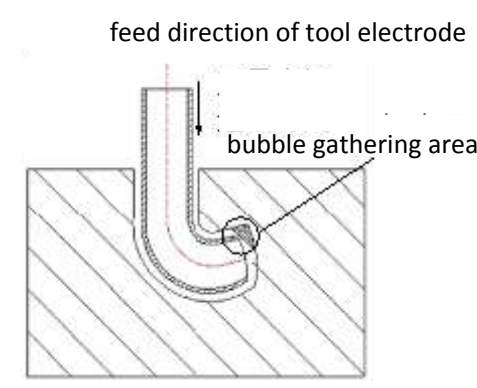

Figure 17. Accumulation of Local Bubble Influencing Electrolytic Removal

However tool electrode working face and the feed direction of tool electrode are at an angle, as shown in Figure 18. Excessive pressure can cause electrolyte fluctuation of tool electrode and impact stability of curve hole electrochemical machining.

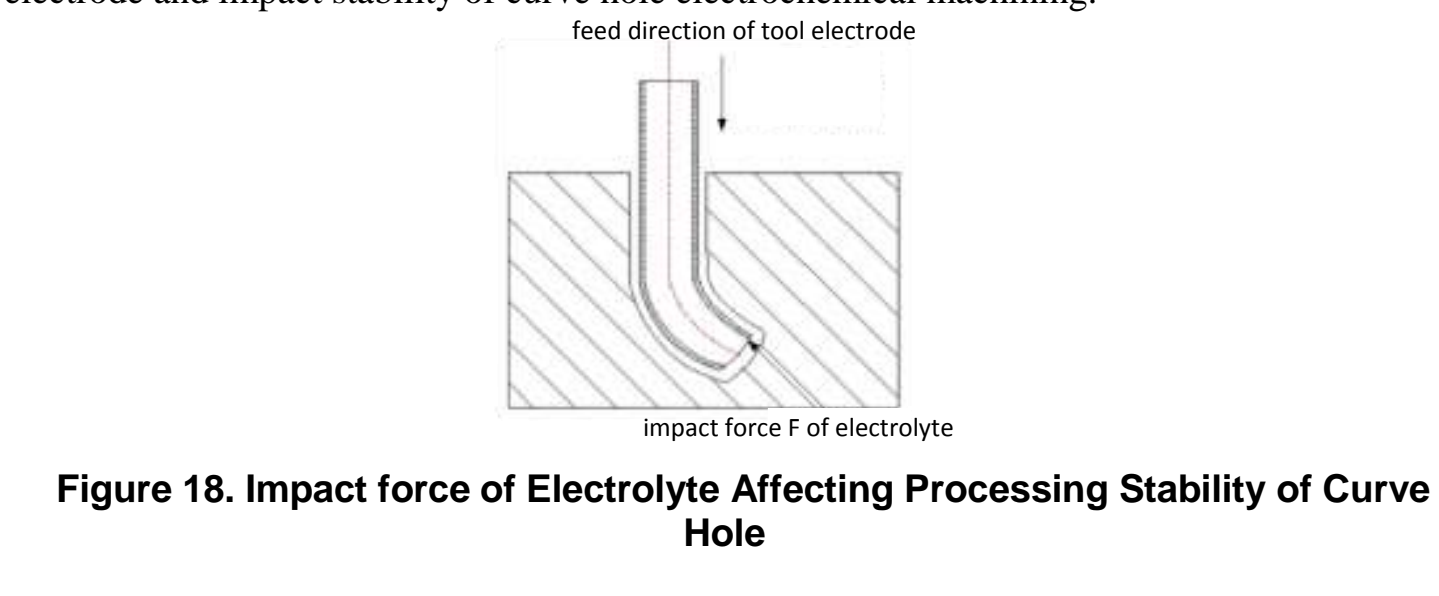

According to simulate machining gap pressure between straight hole and curve hole under the same electrolyte pressure, we know that distribution of pressure field inside machining gap changes significantly when tool electrode bends, as shown in Figure 19 and Figure 20 presents transverse pressure distribution of curve hole front-end gap section A-B. When machining curve hole, distribution of electrolyte pressure inside the machining gap is uneven. Therefore it is more likely to cause the phenomenon of uneven processing and a short circuit to damage machining. 


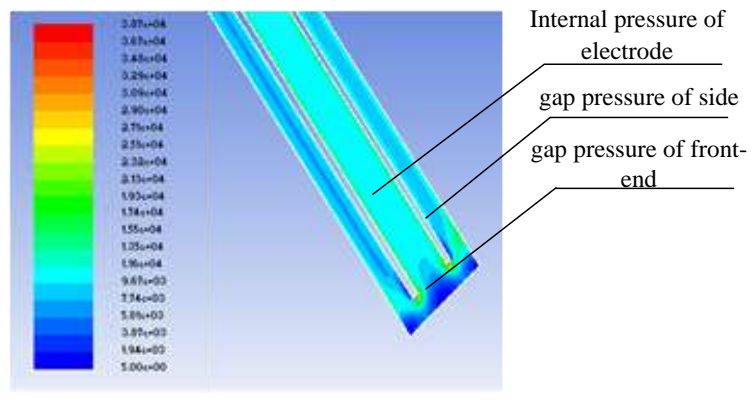

Figure 19. Simulation of Machining Gap Pressure of Curve Hole
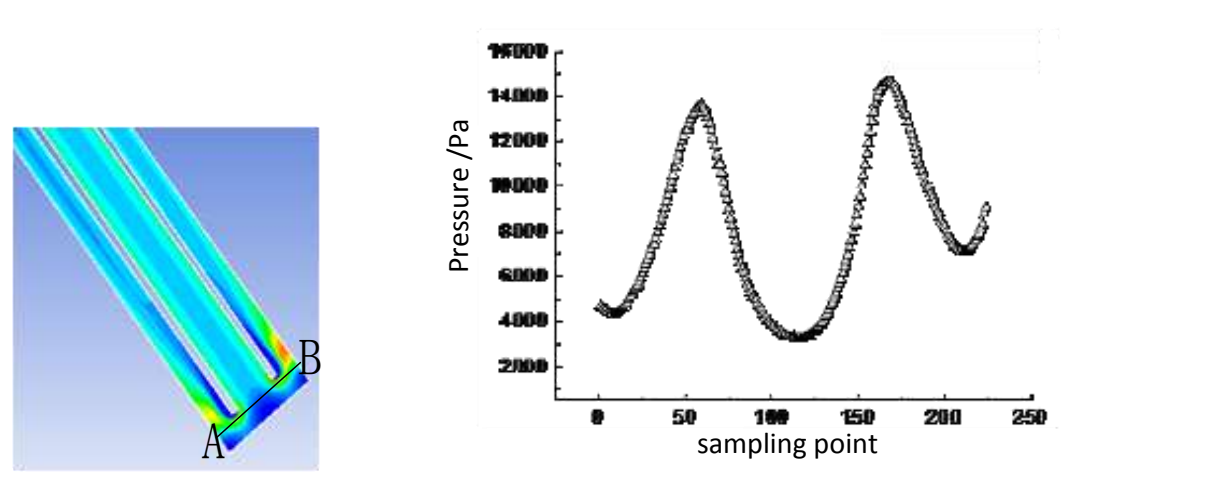

Figure 20. Transverse Pressure Distribution of Curve Hole Front-end Gap

\section{Conclusions}

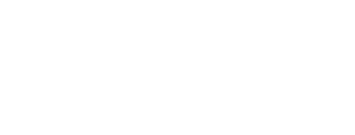

The following conclusions are based on study of effect of electric field distribution on machining holes with ECM.

1) Keep tool feed rate and duty cycle fixed when using pulse power to machine hole Diameter of hole in mverse proportion to tool feed rate and gap current is proportional to tool feed rate. Tool feed rate is inverse proportion to gap of unilateral side of hole and tool feed rate is proportional to gap current.

2) The reason why short circuits occur frequently is that non-metallic film form on the end surface of tubular electrode with the growing processing times. Analyze the mechanism of forming film on the end surface of tubular electrode.

3) Analyze impact of electrolyte pressure on ECM field. Increasing electrolyte pressure will not affect the stability of the gap electric field within a certain range through simulation analysis. (t 1. confirmed by experiments that improving the electrolyte pressure can renew electrolyte effectively, which improves localization of machining hole thereby increasing the accuracy of the shape of the hole.

4) Analyze curve hole ECM field theoretically as well as its simulation. Analyze law of variation of ECM electric field inside the gap and electrolyte pressure distribution when the tubular electrode occurs curvilinear motion. Provide a theoretical basis for curve hole electrochemical machining method. 


\section{Acknowledgements}

The research is funded by supported by Jiangsu Key Laboratory of Precision and Micro-Manufacturing Technology, China Postdoctoral Science Foundation (Grant No. 2015M581461) and Natural Science Foundation of Heilongjiang Province of China (Grant No. E2016044).

\section{References}

[1] Bilgi, D. S., Kumar, R., Jain, V. K., \& Shekhar, R. Int J Adv Manuf Tech. 39(1-2), 47-54 (2008)

[2] Ali S, Hinduja S, Atkinson J, Pandya M. CIRP Ann-Manuf Techn. 58, 185-188 (2009)

[3] Di, S. C., Li, Z. L., \& Wei, D. B. Advanced Materials Research. 199-200, 1874-1879 (2011)

[4] Kozak, J., Rajurkar, K. P., Balkrishna, R., Kozak, J., Rajurkar, K. P., \& Balkrishna, R. J Mater Process Manu.118(4), 490-498 (1996)

[5] Sharma S Jain VK Shekhar R. Int J AdvManuf Technol 19, 492-500 (2002)

[6] Baker G E. SME Non-traditional Machining Symposium.1, 1-12 (1991)

[7] McGeough J A, Pajak P T,De Silva A K M, Harrison D K. Int J Elect Mach. Int J Ad Manuf Technol. 8, 1-14 (2003)

[8] Jain V K, Kanetkar Y, Lal G K. Int J AdvManuf Technol .26: 527-536 (2005)

[9] KozakJ, RajurkarKP, Wei B. Thesis Nebraska Univ. 116(8), 316-323 (1994)

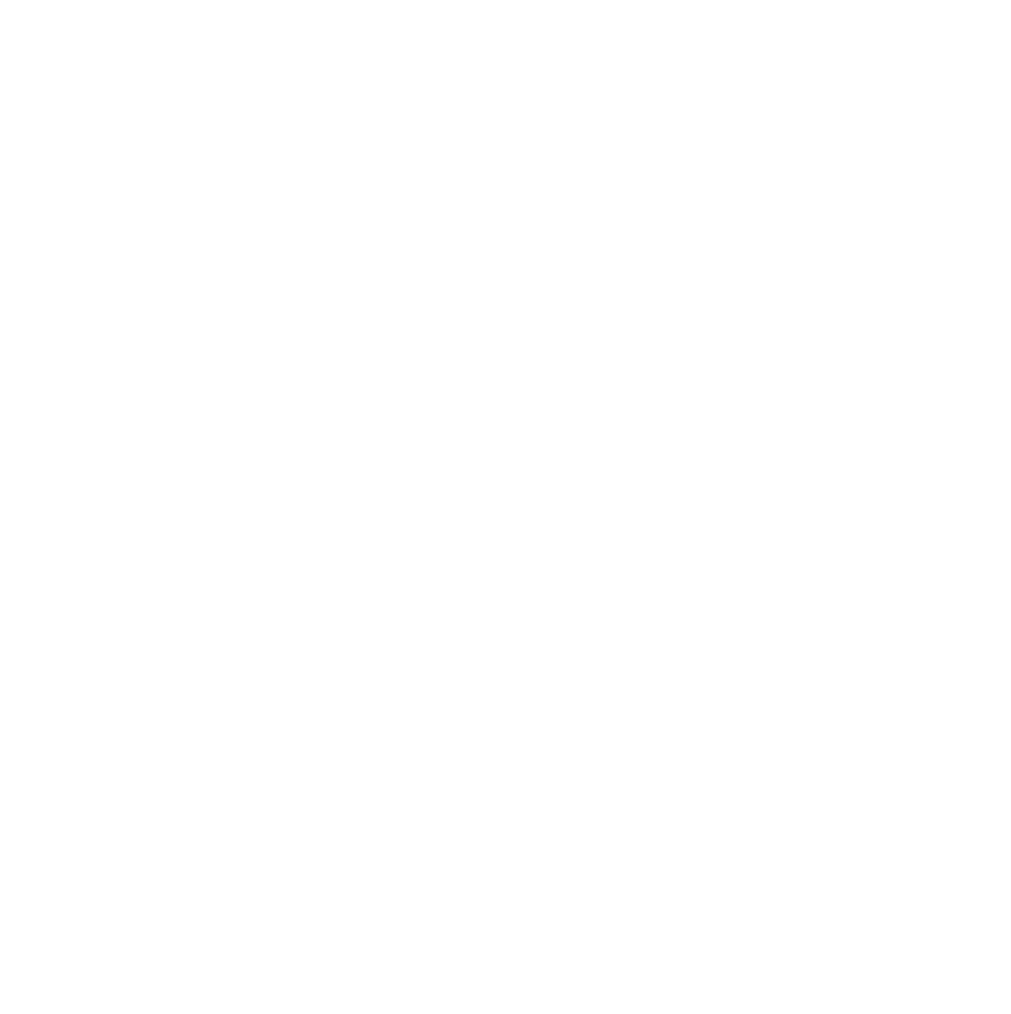


International Journal of Smart Home

Vol.10, No.12 (2016)

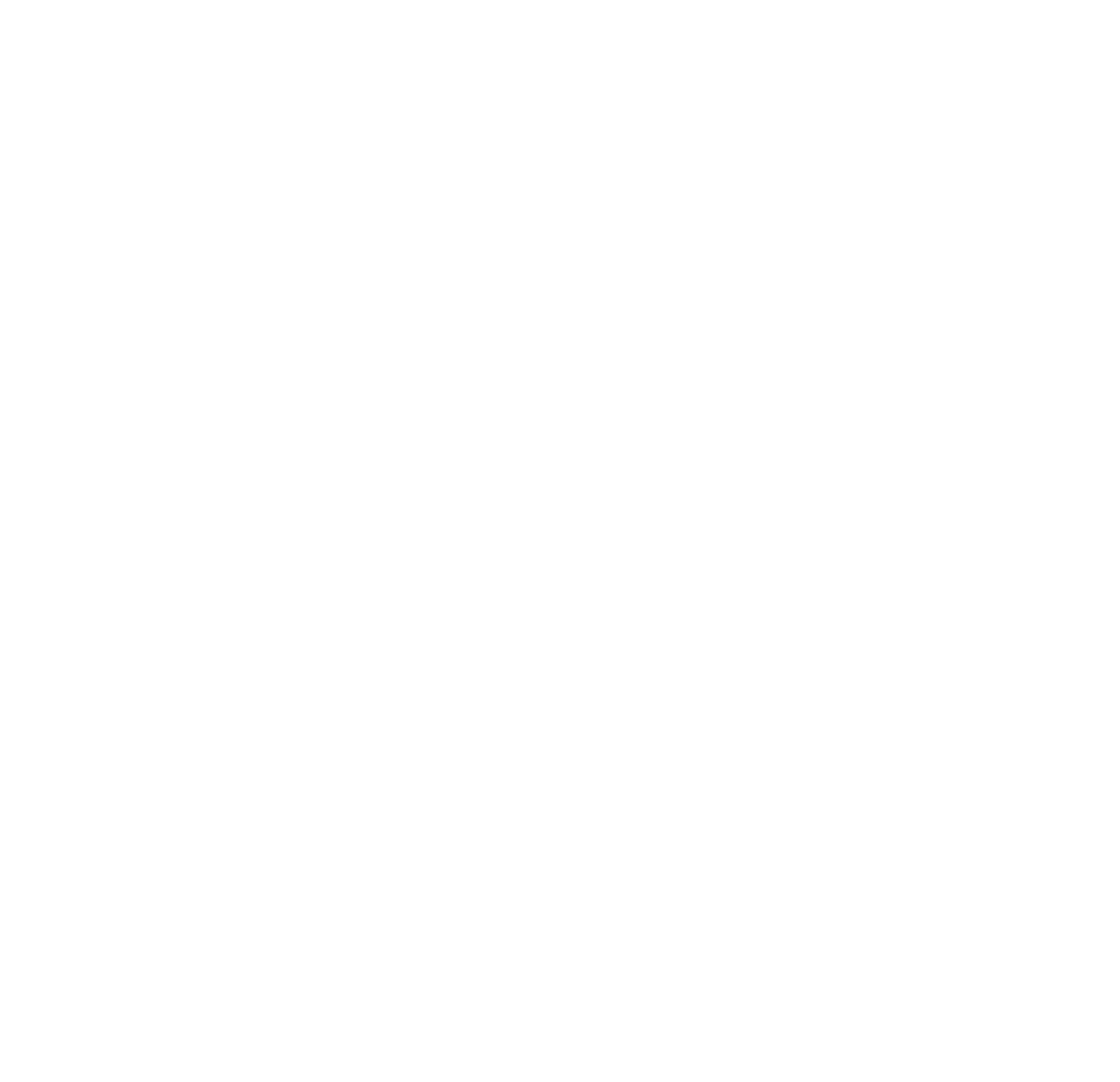

